12

\title{
Charging generalised: a generic role model for charging and billing services in telecommunications
}

\author{
Donald Ranasinghe
}

BT Laboratories, Martlesham Heath, Ipswich IP5 7RE,

United Kingdom

Tel +44 473 642849, fax +44 473637400

E-mail: ranasinghe_d_w@bt-web.bt.co.uk

Jørgen Nфrgaard,

Tele Danmark Research, Lyngsф Allé 2, DK-2970 Hørsholm,

Danmark.

Tel: +454576 6444, fax: +4545766336

E-mail: jnp@tdr.dk

\section{INTRODUCTION}

In current IN charging has a mixed status which obscures the essence of the concept. It is considered 1) as a separate charging SIB and 2) as a service in its own right, such as (credit) Card Calling Service. On examining the service creation in an open broadband environment, charging had to be reconsidered because the card calling service is not a service on its own in the EURESCOM (European Institute for Research and Strategic Studies in Telecommunications, Heidelberg, Germany) project P103 context, but is seen merely as a way of modifying how charging is done for any kind of service. Thus initiating for example, a multimedia conference in a broad band network and have it charged to a calling card [6].

The motivation for this presentation and creation of a generalised charging model will be discussed in relation to EURESCOM Project P103. In this presentation, P103 service creation and composition guidelines will be used to describe a charging service constituent. These guidelines are based on object-oriented concepts from OOram [7, 8], and a service constituent is a reusable unit within service creation. 
The work reported in this paper is ongoing in EURESCOM project P103 - Evolution of the Intelligent Network, therefore not yet finalised, but represents a snapshot of the more mature parts of the project.

The paper is organised as follows, first a short description of the charging problem and a brief introduction to the notations used in the paper. Then the charging service constituents are described in detail and finally a brief discussion of the results.

\section{CHARGING SERVICES IN GENERAL}

The scope of P103 is to define a service framework to support creation of telecommunications services using reusable components and to demonstrate how this service framework can be realised using evolving technology. Background to the project and earlier results can be found elsewhere [9].

The charging service constituent developed in P103 relies on [1], [2], [3], [4] and [5]. The aim of this paper is not to discuss new charging principles, instead it provides a service constituent with parameters and mechanisms for charging which can be applied to any service available in a broadband or in a narrowband network, such as telephony. The starting point for generalised charging in telecommunications services was trying to model the service Card Calling. However, Card Calling service on its own did not make any sense in an environment aiming at reuse. This is because within P103, any service subjected to the core of Card Calling service, should have the usage charge directed to a particular account which may be different from the default one. By generalising charging to be a service constituent that is used by all services, and then leaving it to the charging constituent to actually handle details of charging, it is possible to model services that may be subject to a Card Calling facility.

Charging referred to in this paper is applicable to network operators, service providers, service subscribers and service users for the usage of services.

During the development of the service constituent, no attempt was made to distinguish between charging related to (a) parameters related to subscription (access component) i.e. usage independent parameters and (b) parameters related to the connection (utilisation component) i.e. usage dependent parameters.

\section{EURESCOM PROJECT P103 NOTATION}

In P103 guidelines for the analysis and design of services and service constituents have been defined. The guidelines are based on the object oriented OOram role modelling [10], extended in several ways to meet the project needs. Notations selected are ITU-T Message Sequence Charts (MSC) [12] and ITU-T SDL-92 [11]. The result of applying the guidelines is a set of object types for a service application. The object types can be based on existing role models (service constituents) or on new role models.

In P103 project the term service constituent is used to denote the reusable components which are used to build the service specifications. A service constituent is, in order to be reusable, independent of any particular service but may be applicable to a number of services because it solves some recurring problems in service specifications.

The guidelines consists of three main steps as follows. 
Step 1:

Study the service application and separate it into loosely coupled (independent) Areas of Concern. An area of concern can be viewed as an elementary mechanism with one particular aim. Describe each area of concern in relation to the service application as a whole.

Step 2:

Specify a role model for each area of concern by the use of MSC and SDL. The role model should be a generalised solution to the specific problem to increase the possibility of reuse later. If a similar area of concern already has been specified in terms of a role model this specification can be reused as it is, or as a basis for a new role model.

Step 3:

Map all role models that are necessary in the service application onto a set of object types so that each object type plays one or more roles. The interface and behaviour of each object type is derived from the interfaces and behaviours of each of its roles.

\section{Area of concern}

As with other analysis and design methods, structuring of a service description starts early in the analysis phase and is then used throughout the analysis and design work. The main purpose of this is to break the service down into smaller and easily manageable sub problems. The notion for sub-problem in OOram is area of concern. The way the service is divided into subproblems is perhaps the novelty of OOram. Instead of looking at individual parts or objects of a service, like it would be done with other object oriented methods, the analyst structures according to (part-) functionalities of the service.

An area of concern does not have to be located in one object, instead it may spread over many objects. In fact, objects are implementation related and therefore they are not used in the analysis and design phases of the work.

As a consequence, structuring that originates from a logical understanding of the service and is unlikely anything that may resemble implementation. Thus shifting the attention from what is basically (one) implementation technique to functionality bound structuring.

\section{Stimulus and Response}

When the areas of concern has been determined, the next step is to identify stimulus and responses for each area. Initially an area of concern is characterised by a (prose) description of the area (intentions, purposes, etc.) and a set of stimuli/responses. A stimulus is an event that is not accounted for in the area of concern. However, if it happens, then a certain behaviour will follow, as a response. The response can be anything from a single message being sent to a whole sequence of behaviour.

An example of stimulus for modelling a switch is shown in Figure 1, off-hook, dialling and on-hook and appropriate actions for each one. This gives a way of stating a stimulus the switch model accepts, but not how it is eventually provided. The responses are not shown here. 


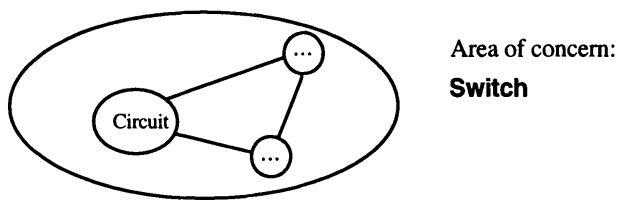

Stimulus: on-hook, off-hook and dialling

Figure 1. Some stimuli for a simple switch.

During the development phase, other role models providing the cause of the stimuli, may be composed for the switch model, thus giving a more comprehensive role model.

One important aspect when getting an input to the role models in this very open manner is that it stresses the externalness of the stimuli which causes an action. In a sense there is essentially no difference between coming from a human user or from another part of the service. It emphasises an autonomous area within in the area of concern with respect to other areas of concern that may exist.

\section{Scenarios}

To get a better understanding of the service being analysed 'use case' scenarios need to be developed, expressing typical communication sequences between entities. The purpose is to get a better understanding of what is going on in the area of concern and what roles are needed. As in many other activities this is an iterative process that may be visited several times.

ITU-TS Message Sequence Charts is a formal notation used for writing down the scenarios. Because MSCs are closely related to SDL-92 this allows easier comparison of MSCs and SDL-92 descriptions.

\section{Role Models}

In general, for each area of concern a role model is built. A role model is a collection of roles (each role having a group of functionalities) and their collaborating structure. A role model containing such a collection of collaborating roles fulfils the requirements in the area of concern.

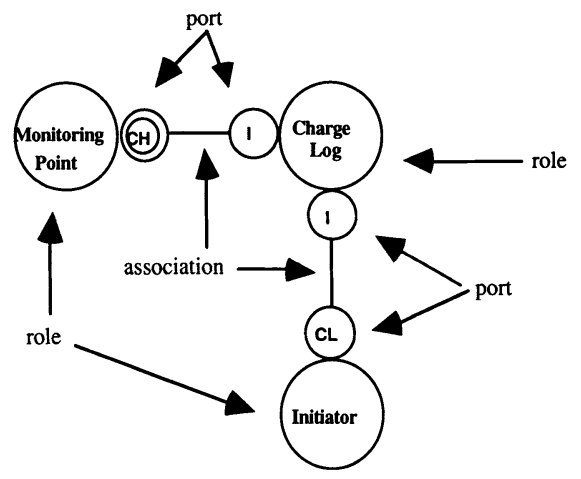

Figure 2. An example role model. 
Roles are associated with each other if they need to communicate. In that case a number of contracts (set of signatures) are specified and positioned in the ports of the roles. In figure 2, the Initiator has a port CL which holds the contracts it has with the role Charge Log. The contract contains the signatures of the operations it expects the Charge Log role to provide, similarly for the Charge Log with its port I.

A role acts as an efficient tool during requirements capture, where the requirements on different parts of the service (-model) are being investigated. It allows "looking" at the rest of the role model from a specific roles's (functionality's) perspective. The role can then state requirement of other roles needed, as collaborating roles. This in reality is a different approach in trying to find requirements by implementing entity's point of view where functionality required is expressed, not the functionality that appears to be necessary. If the roles does not require functionality, it is not written down, even if it appears necessary to the implementor.

During development of the role model, by identifying the roles, the collaborating structure is also determined. It captures the information such as which other role needs to know about a particular role .

The functionality requirements are expressed in contracts between roles and is written down in SDL-92 syntax as signatures for signals, remote procedures and datatypes. SDL-92 is used to avoid the introduction of an intermediate notation (and a mapping problem) before starting to specify the role. Behaviour is specified as a partial process type describing the handling of stimuli and communication, using all available constructs of SDL-92. Such a process type may be specialised.

The goal is to provide service constituents that are not changed later, but only specialised. To achieve this, each transition that may cause a stimuli, has a virtual procedure declared (in the process type) which will be called (in the transition). Thus necessary openings in the behaviour are provided, and none of the already specified behaviour can be accidentally overridden by a specialisation.

\section{Composition: Synthesis}

Having fully designed and specified role models for subproblems of the service, the areas of concern need to be composed. The role models are the result of breaking the service into smaller and more manageable pieces, perhaps recursively if needed. Because the splitting of a service is done differently from most other analysis and design methods, composition will also have to be different. Considering that an area of concern is more than an object, it is obvious that working with usual interfaces alone is probably not enough to complete the job.

Composing means identifying the relations between involved role models and making sure that the causes of stimuli are put together with the parts requiring the stimuli. Because causes of stimulus can come from different places this needs careful consideration. The process of doing composition is called synthesis. Bringing two role models together in synthesis means identifying the roles in the role models where the caused stimuli have to be introduced.

A simple access role model as shown in Figure 3, will cause the stimuli off-hook, on-hook and dialling. 


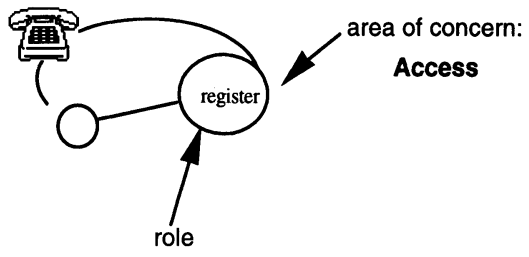

will cause: off-hook, on-hook and dialling

Figure 3 Synthesis.

In P103 the contracts and behaviour is specified in SDL-92. For roles to be synthesised the starting point is the partial process graphs that describe the behaviours of the roles. Because SDL-92 is the formal language being used, communication is either sending messages or making remote procedure calls. This determines the possibilities for interaction. Stimuli for a role model is treated as receiving messages or accepting remote procedure calls under the assumption that any particular stimulus is only accepted in one role.

After having identified the roles that cause stimuli, what remains is to specialise the behaviour to actually generate the stimuli. Each potential cause has its own virtual procedure declaration attached. This declaration may be specialised if the stimuli of some kind have to be generated.

To show how this works in SDL, assume that we have a (partly specified) PROCESS TYPE for the Telephone and we want to specialise that to be the cause of stimuli in the switch.

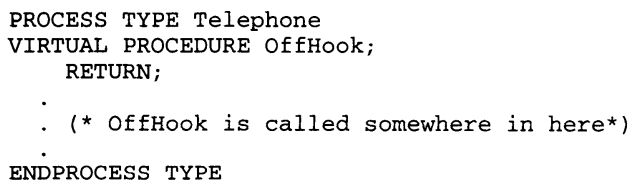

The stimulus is sent to the Switch and the off-hook interaction is resolved by specialising the existing complete specification. There are some technical details left out here, but they are not important for the example illustrated.

\section{CHARGING COMPONENTS}

This presentation discusses a generic charging role model consisting of five roles as shown in Figure 4. Each role in this model will then be decomposed as shown in Figure 6, into a set of relatively low level service constituents related to charging and billing done with a card account. The aim of the decomposed role model is to provide necessary and sufficient details to provide requirements to simulate the charging and billing service constituents (with SDL) 
and check the (behavioural) correctness of the specification. With appropriate test cases, this would provide an opportunity to prove the behavioural aspect of the model.

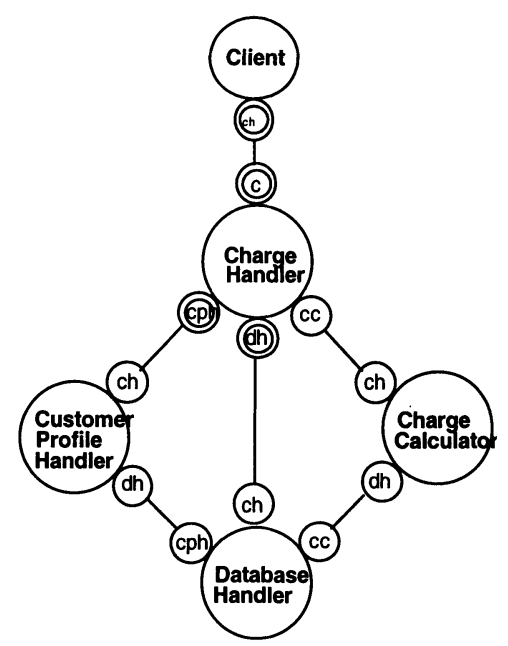

Figure 4. Charging Role model
c - Client
ch - Charge Handler
cc - Charge Calculator
dh - Database Handler
cph - Customer Profile Handler

Table 1. shown below is a typical stimulus-response for the charging area of concern

\begin{tabular}{|l|l|}
\hline Stimulus & Response \\
\hline Transfer the cost of using a service to an & Check that such an operation is permitted \\
account & Ask for the service usage parameters \\
& Store the cost of service \\
& Establish contact with relevant entities \\
& Get parameters for charging purposes \\
& Measure any charging parameters that \\
& affect the quality of service \\
& Give feedback \\
\hline $\begin{array}{l}\text { Calculate the cost of using a service and } \\
\text { give feedback }\end{array}$ & Get parameters for calculation \\
& Calculate cost \\
& Give feedback \\
\hline
\end{tabular}




\begin{tabular}{|l|l|}
\hline $\begin{array}{l}\text { Calculate the potential cost of using a } \\
\text { service (hot billing), given a set of } \\
\text { parameters }\end{array}$ & $\begin{array}{l}\text { Get parameters associated with the } \\
\text { requested service } \\
\text { Calculate cost } \\
\text { Give cost value }\end{array}$ \\
\hline Store the cost of using a service & $\begin{array}{l}\text { Store the cost of the service in an } \\
\text { appropriate format. }\end{array}$ \\
\hline $\begin{array}{l}\text { Give information on service charging } \\
\text { activity }\end{array}$ & $\begin{array}{l}\text { Generate the information requested and } \\
\text { give it in the correct format. }\end{array}$ \\
\hline
\end{tabular}

\section{Roles and Collaborating structure for Charging Aspects}

Based on the stimulus-response described above, a role model for charging was produced as shown in Figure 4.

\section{Client $\{$ Role $\}$}

The Client role represents the stimulus for the role model. The Client role can be replaced with any service, thus making the charging role model adaptable to charge any service, in general.

\section{Charge Handler \{Role\}}

The Charge Handler contains a set of actions and procedures which are associated with a service, in order to determine all the parameters required for calculating service charge. Following functions are its main activities.

- Method(s) for measuring charging information.

- To measure parameters related to charging that affect the quality of service.

- Dispatching the information related to charging activity to those entities that request it.

\section{Charge Calculator \{Role\}}

The Charge Calculator contains method(s) or procedures for calculating service usage.

\section{Database Handler \{Role\}}

Three key activities of the database handler are as follows:

- a storage function, required for the storage of charging information

- to receive charging information.

- to hold information on tariffs applied to charging.

The database handler contains the subscriber account number, CCITT - E.164 address, and the physical locations associated with these addresses. This information is stored and mapped into an address inside the database handler during the whole life of the subscription, from registration to the removal.

The database handler contains charging information related to network usage, service usage and access. 


\section{Customer Profile Handler \{Role\}}

This role contains the information of the customer (Subscriber instance) in relation to:

- Administrative address,

- Physical location,

- Privileges, e.g. service user privileges,

- Services Allowed,

- Customer type,

- Transmission related data,

- Access charging amount,

- PIN code,

- Service access codes and

- authorisation codes.

Figure 5 shows one possible scenario for the charging role model.

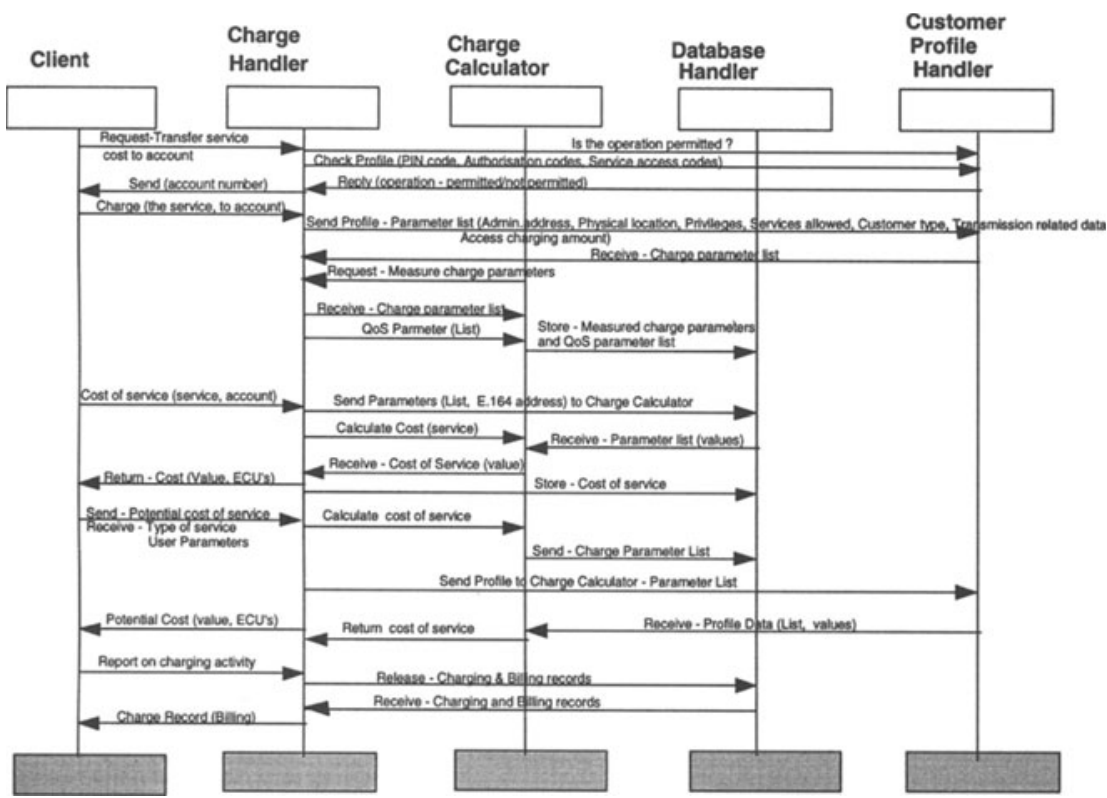

Figure 5. Charging MSC - Message Sequence Chart

Abbreviations used in Table 2 are shown below:

CH - Charge Handler,

CC - Charge Calculator,

DH - Database Handler and

CPH - Customer Profile Handler. 
Table 2. Shown below gives a description of Messages and the Action sequence shown in Figure 5 (Charging MSC)

\begin{tabular}{|c|c|}
\hline $\begin{array}{l}\text { Message from Client (a User or another } \\
\text { Service) }\end{array}$ & $\begin{array}{l}\text { Action by } \mathrm{CH}, \mathrm{CC}, \mathrm{DH} \& \mathrm{CPH} \text { in response } \\
\text { to message from Client }\end{array}$ \\
\hline \multirow[t]{4}{*}{ Request - transfer service cost into account } & $\mathrm{CH}$ to $\mathrm{CPH}$ - Is the operation permitted ? \\
\hline & $\begin{array}{l}\mathrm{CH} \text { to } \mathrm{CPH} \text { - Check Profile (PIN code, Authorisation } \\
\text { codes, Service Access Code) }\end{array}$ \\
\hline & CH to Client - Send account number \\
\hline & $\begin{array}{l}\text { CPH to CH - operation-permitted/not-permitted } \\
\text { authorisation - verify account has funds (black/white } \\
\text { list) }\end{array}$ \\
\hline \multirow[t]{12}{*}{$\begin{array}{l}\text { Charge - the service (Service Provider) } \\
\text { - to account (Network Operator/ Service } \\
\text { Provider/ Service User) }\end{array}$} & $\begin{array}{l}\text { CH to CPH Send Profile - Charge parameter list } \\
\text { (Administration address, Physical location, Privileges - } \\
\text { service user privileges, Services allowed, Customer } \\
\text { type, Transmission related data, Access charging } \\
\text { amount) }\end{array}$ \\
\hline & CPH to $\mathrm{CH}$ - Receive charge parameter list \\
\hline & $\mathrm{CH}$ to $\mathrm{CC}$ - Calculate charge \\
\hline & $\mathrm{CC}$ to $\mathrm{CH}$ - Request "measure charge parameters" \\
\hline & CH to CC - Receive "charge parameter list" \\
\hline & CH to CC - Receive "QoS parameter list" \\
\hline & $\begin{array}{l}\text { CC to DH - Store "measured charge parameters, QoS } \\
\text { parameter list and calculated cost of service" }\end{array}$ \\
\hline & $\begin{array}{l}\text { CH to Client - Allow access to list of parameters related } \\
\text { to service cost and tariffs associated with service }\end{array}$ \\
\hline & $\mathrm{CH}$ to $\mathrm{CC}$ - Receive measured charge parameters \\
\hline & CH to CC - Calculate cost of service \\
\hline & CH to CC - Receive QoS - list of parameters \\
\hline & $\begin{array}{l}\text { CC to DH - Store measured parameters \& calculated } \\
\text { cost }\end{array}$ \\
\hline \multirow[t]{5}{*}{$\begin{array}{l}\text { Cost of service - to pay a service in real-time / } \\
\text { debit to an account }\end{array}$} & $\begin{array}{l}\text { CH to DH - Send charge parameters (list), E. } 164 \\
\text { address, and tariffs to CC }\end{array}$ \\
\hline & DH to CC - Receive charge parameter list and tariffs \\
\hline & $\mathrm{CH}$ to $\mathrm{CC}$ - Calculate the cost of service \\
\hline & $\begin{array}{l}\mathrm{CH} \text { to DH - Store calculated cost of service at E.164 } \\
\text { address }\end{array}$ \\
\hline & $\begin{array}{l}\mathrm{CC} \text { to } \mathrm{CH} \text { - Return cost of service to Client - Billing - } \\
\text { value (ECU's) }\end{array}$ \\
\hline \multirow{3}{*}{$\begin{array}{l}\text { Potential cost of service usage (for paying a } \\
\text { service) - Type of service / user parameters to } \\
\text { establish cost (real-time usage of service) }\end{array}$} & $\mathrm{CH}$ to $\mathrm{CC}$ - Calculate the cost of service usage \\
\hline & $\begin{array}{l}\text { CH to CC - Receive Tariffs, Access charge and User } \\
\text { parameters }\end{array}$ \\
\hline & CPH to CC - Receive profile data (list, values) \\
\hline
\end{tabular}


6. Provide report on charging activity - Billing with user parameters
Request from $\mathrm{CH}$ to $\mathrm{DH}$ - Release records of charging activities to Client

CH to Client - Receive charging records

\section{Further Subdivision of the Charging Constituent}

The overall charging role model shown in Figure 4, is decomposed into a number of smaller constituents, which focus on particular aspects of functionality.

Figure 6, shows role models for the aspects of Usage Charging, Account Handling, Account Selection and Payment Selection.

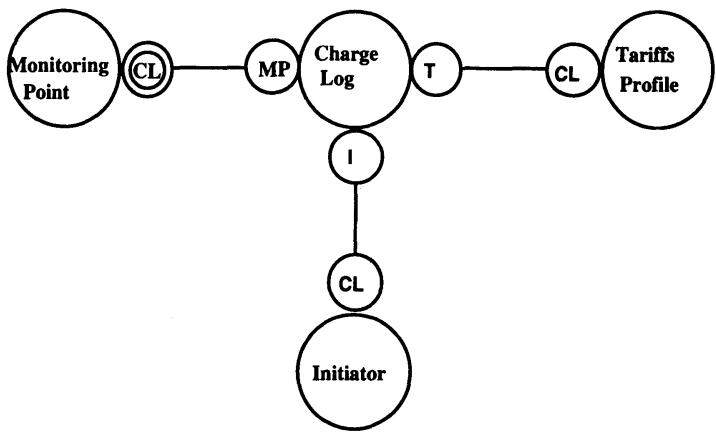

Figure 6(a). Usage charging role model

Figure 6(a) shows the role model concerned with charging a user of a service on behalf of the owner of the service. In general, a user can be a person or another service.

\section{Following are the stimuli which occur in this role model.}

1. The initiator decides to start charging the user. The initiator sends a start_charging message to the charge log. The charge log starts to register all charge related events. If the charge log is unable to execute this task, then a failure message is sent to the initiator.

2. The initiator stops charging the user, and sends a stop_charging message to the charge log. This terminates the action of the charge log i.e. suspend logging of all charge related events.

3: A monitoring point detects a change in the charge state of a resource and reports the change to the charge log. This causes an update in the charge register.

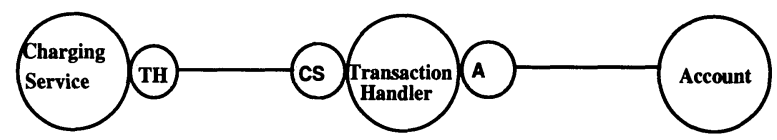

Figure 6(b). Transaction handling role model 
Figure 6(b) shows the role model concerned with the registration of a payment transaction on the account of a service user (e.g. a credit card account). The transaction must contain an identification of a receiver of the payment (normally the owner of the service) and the amount to be paid.

\section{Following are the stimuli which occur in this role.}

1. The charged service decides to start the transfer of charge to the account handler. This follows an initialise message from the charged service to the account handler. The account handler receives a credit_limit from the account and returns a ready message to the charged service.

2. The charged service sends charge state information to the account handler. The account handler compares accumulated charge with the credit_limit. If the credit_limit is exceeded, account handler withdraws the credit limit from the account and closes the account. This follows the message credit_limit_exceeded from account handler to the charged service.

3. The account handler detects (based on the current charge rate) that the credit_limit is likely to be exceeded and sends the credit_limit_exceeded message to the charged service.

4. Termination of the charged service - The charged service sends a stop message to the account handler, withdrawing the accumulated charge from the account followed by the closure of the account.

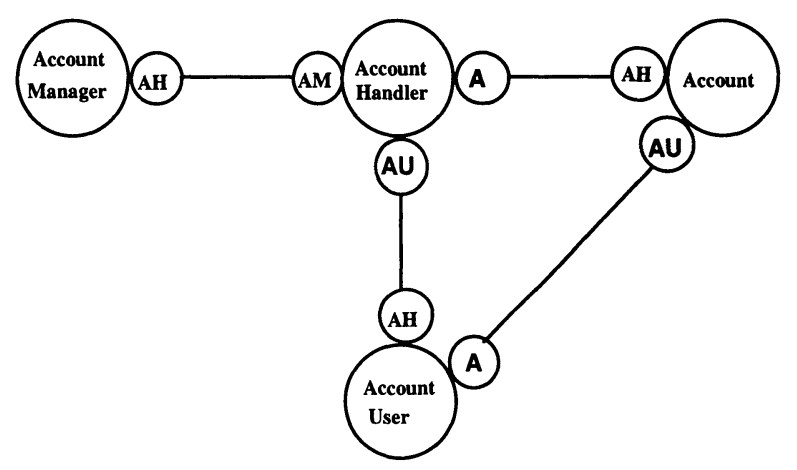

Figure 6(c). Account selection role model

Figure 6(c) shows the account selection role model. This role model is concerned with the selection and initialisation of an account for an account user. An account manager is responsible for selecting the account to be used. An account manager identifies the account to be used. The selected account is then initialised. If the account cannot be initialised a failure message is sent to the account manager and the account user.

\section{Following stimulus occurs in this role model.}

1. The account user needs an account reference. The account user sends a get_account message to the account initialiser. The result of the account initialisation is returned to the account user together with a reference to the account. 


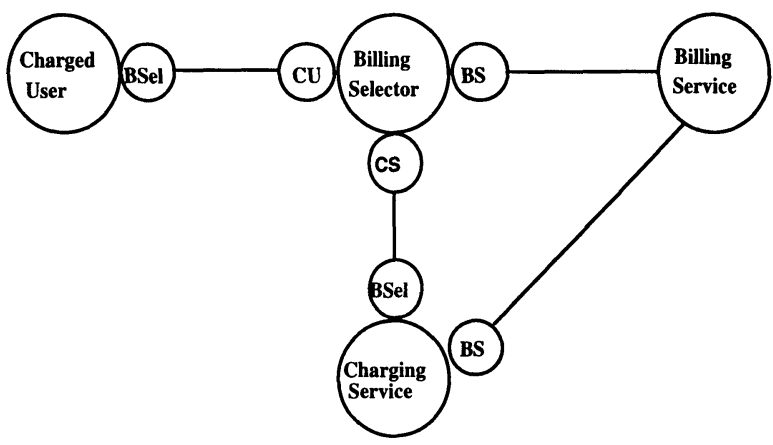

Figure 6(d). Billing selection role model

Figure 6(d) shows the billing selection role model. This role model is concerned with the selection of a billing service for a charged user. The user who is charged for the usage of a service is given the option to select the type of billing service to be used e.g. coin box billing, credit card account, standard method by the owner of the charging service, prepaid telecom cards ect. It is assumed that different ways of paying for a service may require different software implementations. Therefore, it would be necessary to invoke the kind of billing service chosen by the user.

\section{Following stimulus occurs in this role model.}

1. The charged service requires a reference to a billing service. The charged service sends an initialise message to the billing selector. The billing selector will return the result of the billing selection to the charged service together with the reference to the selected payment service.

The service constituents described in this paper would be incomplete without the appropriate role models for user authentication and the service network charging. These role models are discussed in detail within the EURESCOM P103, PIR (Project Internal Report) 1.5, Issue 2. However, the synthesised role model for charging and billing shown in Figure 4, and the message sequence chart shown in Figure 5 has accounted for these two role models during its synthesis.

\section{DISCUSSION AND FUTURE WORK PLAN}

The discussion in this paper is centred around a proposal to generalise the concept of charging as a service constituent that may be used from any service in a network. By having a charging service constituent, the service specifications does not have to include aspects that have to do with charging. Thus, allowing any service to be charged to a calling card, as opposed to the card calling services currently in use. This is recognised as an important property that can be applied in networks, which may contain a great variety of services and many different charging policies. Future work include consolidating and detailing the descriptions of the constituents and to specify their behaviour. 


\section{ACKNOWLEDGEMENTS}

The work reported in this paper is based on intermediate results from EURESCOM collaborative project P103, Task 1 where the following have contributed to the work Bengt G Jensen and Knut Lillegraven from Norwegian Telecom Research (Kjeller, Norway), Parminder Mudhar from BT Laboratory (Ipswich, UK), Lars Pedersen from Tele Danmark Research (Horsholm, Danmark) and Roberto Minetti from CSELT (Turin, Italy).

\section{REFERENCES}

[1] ETSI/NA5 technical report "Parameters and mechanisms relevant for charging in B-ISDN" DTR/NA-52204.

[2] EURESCOM P105 "European ATM network studies" (Deliverable No.3, Volume 2 of 4: Network Management - Parameters for Charging and Accounting).

[3] CCITT Recommendation D-Series (03/93), D.000, D.98, D.178, D.120

[4] The EURESCOM P103, Project Internal Report 1.5 Service Constituents, Issue 1, (EntityRelationship Diagrams of the Card Calling Service).

[5] The 1988 CommEd Proceedings on Telecommunications Billing and Charging (London), CommEd Ltd, 137, Dulwich Road, London SE2 0NG, UK.

[6] EURESCOM P103, Project Internal Report, 1. 4, (July 1994).

[7] Presentations of the method at IEEE IN ' 94 Workshop Records Volumes 1 \& 2. (May 24 26,1994, Ramada Renaissance Hotel, Heidelberg, Germany).

[8] EURESCOM P103, Project Internal Report, 1.1 - Scene Setting.

[9] "Object oriented IN service provision" R. Nilsen, J. Simons and P.Dellafera, The fourth Telecommunications information Networking Architecture Workshop, 1993, pp I-233 - I245.

[10] Reenskaug, T et al. "OORASS", Seamless support for the creation and maintenance of object oriented systems" In: Journal of Object-Oriented Programming (Oct. 1992).

[11] Recommendation Z.100 - SDL, ITU-T, 1992, Revised Recommendation.

[12] Recommendation Z.120 “Message Sequence Charts, MSC," ITU-T, 1992. 